\title{
P02.62. DHEA augmentation strategy for treatment of fatigue and depression: a case presentation
}

\author{
R Glick ${ }^{*}$ X Jimenez \\ From International Research Congress on Integrative Medicine and Health 2012 \\ Portland, Oregon, USA. 15-18 May 2012
}

\section{Purpose}

Dehydroepiandrosterone (DHEA) and its sulfated derivative DHEA-S are endogenous hormones secreted by the adrenal cortex in response to ACTH and stress. Levels of DHEA and DHEA-S are decreased with advancing age and depression. Trials of DHEA for mid-life depression have shown promising yet inconclusive results, due in part to small sample sizes and lack of placebo comparators. An additional concern, with the risk of breast cancer in this age group, is the high doses of DHEA supplementation used. We present a case in which low-dose topical DHEA and other hormonal agents were used as an adjunct to conventional antidepressant therapy to target symptoms of depression and fatigue in a peri-menopausal woman.

\section{Methods}

Baseline levels of DHEA-S were collected. In addition, we assessed fatigue and depression using PROMIS measures and vitality based on the SF-36. DHEA/Pregnenolone/ Progesterone topical cream, dosed at 10/20/50 mg/mL per day, was added to the patient's usual treatment regimen of fluoxetine $20 \mathrm{mg}$ daily.

\section{Results}

Baseline labs revealed DHEA-S level of 63 (ref range: 15170). Baseline questionnaires revealed fatigue at $25 / 35$ (moderate-severe), depression at 23/40 (moderate), and vitality at 8/24 (low). After 12 months of treatment, DHEA-S was slightly increased at 83 and rating scores included fatigue at 11 (mild), depression 10 (mild) and vitality at 19 (high). A decrease of fluoxetine to $10 \mathrm{mg}$ daily was well tolerated and no adverse effects were seen with treatment.

University of Pittsburgh School of Medicine, Pittsburgh, USA

\section{Conclusion}

Given its safety and efficacy profile, low-dose topical DHEA adjunctive treatment for fatigue and depression in mid-life may result in well-tolerated improvements in subjective measures of fatigue, depression, and vitality, and warrants further investigation. Future investigation in a placebo-controlled, RCT is warranted. Such studies should assess safety and tolerability, effect on downstream hormones such as estradiol, optimal dosing, and impact on mood.

Published: 12 June 2012

doi:10.1186/1472-6882-12-S1-P118

Cite this article as: Glick and Jimenez: P02.62. DHEA augmentation strategy for treatment of fatigue and depression: a case presentation. BMC Complementary and Alternative Medicine 2012 12(Suppl 1):P118.

Submit your next manuscript to BioMed Central and take full advantage of:

- Convenient online submission

- Thorough peer review

- No space constraints or color figure charges

- Immediate publication on acceptance

- Inclusion in PubMed, CAS, Scopus and Google Scholar

- Research which is freely available for redistribution 